\title{
Digital Epidemiologic Research on Multilevel Risks for HIV Acquisition and Other Health Outcomes Among Transgender Women in Eastern and Southern United States: Protocol for an Online Cohort
}

Andrea L Wirtz ${ }^{1}$, PhD; Erin E Cooney ${ }^{1}$, MSPH; Megan Stevenson ${ }^{1}$, MSPH; Asa Radix ${ }^{2}, \mathrm{MD}, \mathrm{PhD}$; Tonia Poteat ${ }^{3}$, $\mathrm{PhD}$, PA-C; Andrew J Wawrzyniak ${ }^{4}$, PhD; Christopher M Cannon ${ }^{5}$, MPH; Jason S Schneider ${ }^{6}$, MD; J Sonya Haw ${ }^{6}$, MD; James Case ${ }^{7}$, MBI; Keri N Althoff ${ }^{1}$, PhD; Elizabeth Humes ${ }^{1}$, MHS; Kenneth H Mayer ${ }^{8,9}$, MD; Chris Beyrer ${ }^{1}$, MD; Allan E Rodriguez ${ }^{10}$, MD; Sari L Reisner ${ }^{9,11,12,13}$, SCD; American Cohort To Study HIV Acquisition Among Transgender Women (LITE) Study Group ${ }^{1}$

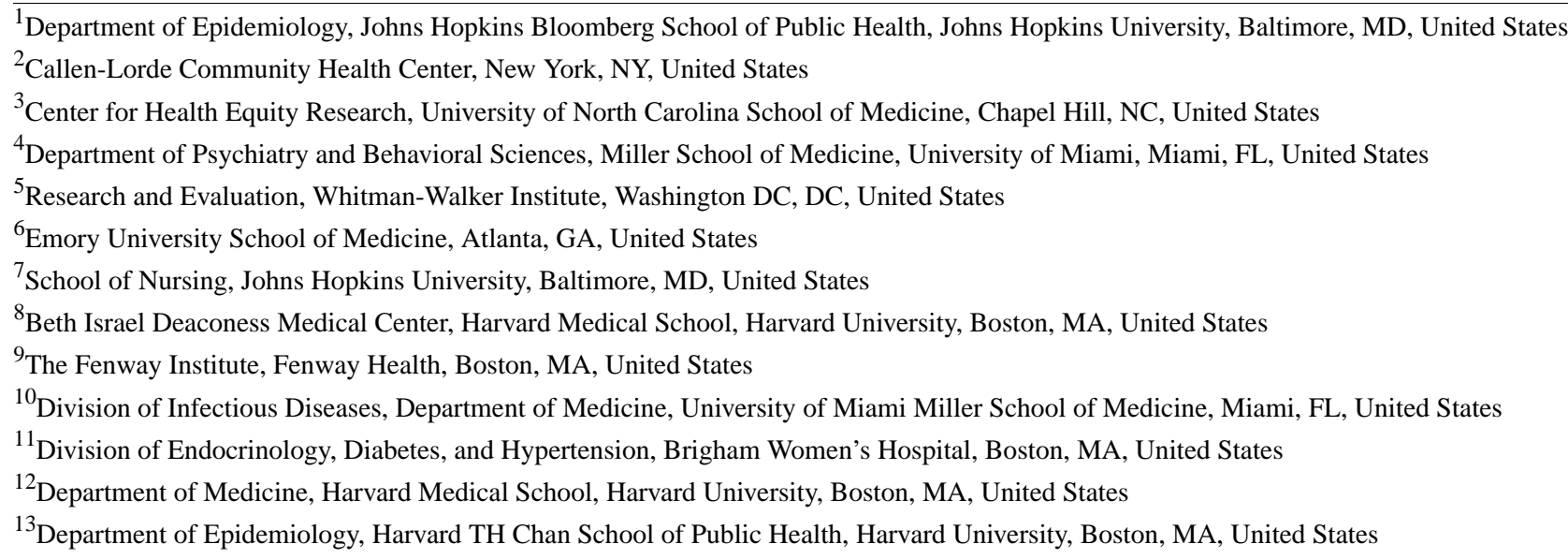

Corresponding Author:

Andrea L Wirtz, PhD

Department of Epidemiology

Johns Hopkins Bloomberg School of Public Health

Johns Hopkins University

$615 \mathrm{~N}$ Wolfe St

W3505

Baltimore, MD, 21205-4803

United States

Phone: 14105020800

Email: awirtz1@jhu.edu

\begin{abstract}
Background: The HIV epidemic disproportionately impacts transgender women in the United States. Cohort studies identify unique risks for affected populations, but use of facility-based methods may bias findings towards individuals living in research catchment areas, more engaged in health services, or, in the case of transgender populations, those who are open about their transgender identity. Digital clinical trials and other online research methods are increasingly common, providing opportunity to reach those not commonly engaged in research. Simultaneously, there is a need to understand potential biases associated with digital research, how these methods perform, and whether they are accepted across populations.

Objective: This study aims to assess the feasibility of developing and implementing an online cohort of transgender women to assess risks for HIV acquisition and other health experiences. Further, this study aims to evaluate how an online cohort compares to a site-based, technology-enhanced cohort for epidemiologic research. The overarching goal is to estimate incidence of HIV and other health outcomes among transgender women in eastern and southern United States.
\end{abstract}


Methods: This substudy is part of a larger multisite prospective cohort (LITE) conducted among transgender women, which also includes a site-based, technology-enhanced cohort in 6 eastern and southern US cities. The online cohort was launched to enroll and follow participants across 72 cities in the same region and with similar demographic characteristics as the site-based cohort. Participants are followed for 24 months. Adult transgender women are recruited via convenience sampling (eg, peer referrals, social media, and dating apps). Participants reporting negative or unknown HIV status are enrolled in a baseline study visit, complete a sociobehavioral survey, and provide oral fluid specimens to test for HIV. Participants not living with HIV (lab-confirmed) at baseline are offered enrollment into the cohort; follow-up assessments occur every 6 months.

Results: Enrollment into the online cohort launched in January 2019. Active recruitment stopped in May 2019, and enrollment officially closed in August 2020. A total of 580 participants enrolled into and are followed in the cohort. A recruitment-enrollment cascade was observed across screening, consent, and completion of study activities. Implementation experiences with HIV test kits highlight the need for heavy staff engagement to support participant engagement, visit completion, and retention, even with automated digital procedures.

Conclusions: This study is responsive to increasing research interest in digital observational and intervention research, particularly for populations who are most affected by the HIV epidemic and for those who may otherwise not participate in person. The progression across stages of the recruitment-enrollment cascade provides useful insight for implementation of cohort studies in the online environment.

International Registered Report Identifier (IRRID)： DERR1-10.2196/29152

(JMIR Res Protoc 2021;10(4):e29152) doi: $\underline{10.2196 / 29152}$

\section{KEYWORDS}

transgender persons; United States; cohort studies; digital research; HIV infection; HIV testing; public health; online health; transgender; HIV

\section{Introduction}

\section{Background}

Transgender women are one of the most affected populations with respect to the HIV epidemic in the United States and are prioritized in the US strategy to end the HIV epidemic $[1,2]$. Multiple biological, behavioral, and social risks for HIV infection among transgender women are driven by, or are concomitant with, structural barriers that limit access to HIV prevention, testing, care, and health services [3]. Across the United States, transgender women report a high prevalence of sexual assault and violence, homelessness, unemployment, substance use, and low health insurance coverage [4-12]. These factors increase the likelihood of condomless sex, thereby increasing HIV acquisition risk. Due to these multilevel vulnerabilities, transgender women in the United States experience an estimated $14 \%$ laboratory-confirmed HIV prevalence (meta-analysis) - more than 42 times the national HIV prevalence in the United States of $0.3 \%$ [13]. Significant disparities exist across racial groups and ethnicity: HIV prevalence is estimated to be $44 \%$ among Black transgender women and 25\% among Latina transgender women [13]. Gender-based discrimination, stigma in health care, and prioritization of basic needs, including gender-affirming care, impede access and uptake of HIV testing, prevention, care, and treatment $[12,14,15]$. Effective and acceptable HIV prevention interventions tailored to transgender women are urgently needed and require population-specific insight gained from observational and qualitative research [16-21].

HIV prevention research among transgender women faces several challenges. The lack of transgender-specific marketing and misgendering during research (referring to a person by an incorrect name or pronoun) have left a legacy of wariness about
HIV research [22]. Inclusion of transgender women as a subset of a larger study population has produced small samples of transgender women, limited scientific inference, and provided insufficient information about acceptable and effective HIV prevention interventions. Despite prior participation in HIV research, transgender women participants have reported that these efforts rarely benefit their communities [22], highlighting the importance of population-specific and community-engaged research to identify and respond to community needs.

In March 2018, we launched the first multisite cohort to assess HIV incidence among transgender women in the United States (known to participants as the LITE study; NIH UG3/UH3AI133669). This cohort has enabled the development and refinement of technology-enhanced methods to reach and retain transgender women in site-based HIV research. The cohort includes 6 technology-enhanced, site-based cohorts in Boston, New York City, Baltimore, Washington DC, Atlanta, and Miami, providing a combination of facility-based in-person and remote assessments for participants over at least 24 months of follow-up [23]. Facility-based visits include self-administered surveys along with HIV and sexually transmitted infection (STI) testing. During remote visits, participants utilize a hybrid app to complete surveys and HIV self-testing, report the results, and upload photos of the test results for validation. This method allowed us to enroll and retain 731 transgender women with varying levels of consistent technology access across these 6 cities.

Cohort studies identify unique risks for affected populations, but the traditional use of facility-based methods may bias findings towards individuals living in research catchment areas, more engaged in health services, or, in the case of transgender populations, those who are open about their transgender identity. Novel, technology-based methods are rapidly increasing in 
popularity across multiple facets of epidemiologic research. Outside of HIV research, several large cohorts, such as the NIH's Precision Medicine Initiative Cohort [24] and the Black Women's Health Study [25], recruit and follow up to 1 million participants across the United States using predominantly technology-based methods. Technology is increasingly integrated into HIV research through sampling and recruitment methods via online advertisements on social media and dating apps as well as electronic peer referral methods [26,27]; electronic and remote data collection [28-30]; and remote specimen collection for biologic measures [31-33]. These tools have permitted enrollment of large samples of participants for behavioral surveys [34-36], cohort research [37-39], and intervention research $[40,41]$. The development of SMS and smartphone apps has become an increasingly common method to deliver prevention and care interventions [42-45], while gaming methods have been incorporated to maintain participant engagement, particularly among youth, in research activities and to promote health behaviors $[45,46]$. The potential benefits of improving overall study efficiency, reducing study costs associated with space and staff needs for data collection, and improving convenience for participants suggest that integration of technology into research practices will continue to emerge, expand, and evolve. Yet, counter to these anticipated benefits, there remain questions related to potential biases, additional technology and staff costs, long-term retention, relationship building with communities and participants, participant privacy and security, and feasibility in terms of how these methods perform among diverse populations. Most research efforts focus exclusively on online or site-based cohort methods, limiting the ability to answer these questions.

\section{Objectives}

The objective of the online cohort is to assess the feasibility and qualitative differences in the development and implementation of an online cohort compared to a site-based, technology-enhanced cohort for HIV research. This online cohort will also contribute to the broader aims of the LITE study, which are to (1) determine the efficiency and acceptability of novel, technology-infused recruitment methods to enroll HIV-uninfected transgender women into a prospective cohort; (2) describe the demographic, socioeconomic, behavioral, and physical and mental health profiles of HIV-uninfected transgender women in the eastern and southern United States; (3) estimate HIV incidence among transgender women in high-risk eastern and southern US areas, trends in incidence, and associated individual, social, and structural risk factors; and (4) estimate the HIV Prevention Continuum (HIVPC) among HIV-uninfected participants and the HIV Care Continuum (HIVCC) among transgender women who acquire HIV over the course of follow-up [23]. The overarching goal of these cohorts is to inform subsequent HIV prevention, HIV care, and other health interventions that are developed explicitly to meet the unique health needs of transgender women.

\section{Methods}

\section{Design}

This protocol describes the methods of a "sister" online cohort for transgender women in eastern and southern United States. Online cohort methods are largely developed to match the site-based methods conducted under the LITE study, to the closest extent possible, which has previously been described [23]. The protocol described here provides an overview of the online cohort methods, highlighting distinctions between the online and site-based cohorts. Notably, the online cohort utilizes strictly remote study assessments that include self-administered, electronic surveys and the use of self-collected, oral fluid specimens, which are shipped to a central laboratory for HIV-1 testing. Study assessments occur every 6 months, rather than quarterly visits as in the site-based cohorts. STI testing is not performed due to resource constraints.

All cohort methods have been informed by formative qualitative research, which focused on assessing community perspectives of technology-enhanced and online research methods, HIV testing methods, concerns and suggestions related to HIV research among transgender women, and optimal ways to engage the community $[22,47,48]$.

A virtual community advisory board ( $\mathrm{CAB}$ ) facilitates this research by serving as a mechanism for community consultation for both the site-based and online cohorts and is engaged throughout every phase of the research activities. CAB meetings are held every 4-6 months to discuss research activities, concerns and protection of community members, results, and plans for dissemination to the wider community $[49,50]$.

\section{Sample}

The online cohort enrolled and follows adult transgender women who are not living with HIV in 72 eastern and southern US metropolitan areas with population sizes $>100,000$. Participating cities for the online cohort were selected on the basis of similar demographic characteristics to the initial 6 cities (Boston, New York City, Baltimore, Washington DC, Atlanta, and Miami) where the site-based cohort is implemented.

Preliminary, self-administered screening assesses for the following inclusion criteria: aged 18 years or older; no prior diagnosis of HIV infection; speaks and understands English or Spanish; and residence in or within a 90-mile radius of one of the following cities: Atlanta, GA; Baltimore, MD; Baton Rouge, LA; Birmingham, AL; Boston, MA; Charlotte, NC; Chicago, IL; Columbia, SC; Detroit, MI; Jackson, MS; Jacksonville, FL; Memphis, TN; Miami, FL; Nashville, TN; New Haven, CT; New Orleans, LA; New York, NY; Newark, NJ; Orlando, FL; Philadelphia, PA; Pittsburgh, PA; Providence, RI; Tampa, FL; Washington, DC; Worcester, MA; Allentown, PA; Aurora, IL; Bridgeport, CT; Buffalo City, NY; Charleston, SC; Charlotte, $\mathrm{NC}$; Chattanooga, TN; Cincinnati, OH; Clarksville, TN; Cleveland, OH; Columbus, GA; Columbus, $\mathrm{OH}$; Fayetteville, NC; Flint, MI; Fort Wayne, IN; Ft. Lauderdale, FL; Hartford, CT; Hollywood, FL; Huntsville, AL; Indianapolis, IN; Jersey City, NJ; Knoxville, TN; Lafayette, LA; Lansing, MI; Lexington, KY; Louisville, KY; Mobile, AL; Montgomery, AL; 
Norfolk, VA; Palm Bay, FL; Port St. Lucie, FL; Raleigh/Durham, NC; Richmond, VA; Rochester City, NY; Rockford, IL; Savannah, GA; Shreveport, LA; Springfield, NC; Stamford, CT; Syracuse, NY; Tallahassee, FL; Tampa/Clearwater/St. Petersburg, FL; Toledo, OH; Virginia Beach/ Newport News, VA; Waterbury, CT; Wilmington, NC; and Yonkers City, NY. Participants' transgender status was determined during screening using the recommended two-step method (assigned male sex at birth and current gender identity as a woman or along the trans feminine spectrum) [51,52], inclusive of binary and nonbinary people. Participants who were eligible based on preliminary screening and provided electronic consent to participate were then asked to complete the baseline survey and are sent an oral fluid specimen collection kit for laboratory verification of HIV status and final determination of eligibility in the cohort.

Prior to the consent and enrollment process, participants were asked to complete a 2-factor authentication process (to ensure they are not duplicate enrollees or robotic enrollments). Individuals who are duplicate enrollments or who report concurrent enrollment in an HIV prevention trial were ineligible for participation.

\section{Recruitment and Enrollment}

Recruitment utilized a mix of technology-infused methods, including paid advertisements on Google Ads; social media venues frequented by transgender women including Facebook, Instagram, and Reddit; as well as geosocial networking apps used for dating (eg, Grindr and Black Gay Chat; Figure 1). Online advertisements for these sites permitted targeting of ads to the specified cities and surrounding areas, user profiles, or user search terms based on internal algorithms (no individual-level identifying data are shared with researchers). Our study website synchronized with Google Analytics to permit real-time analysis of geographic locations of users, keywords, and sites that referred them, which allowed us to monitor and adjust recruitment strategies as enrollment proceeded.

Figure 1. Image of a social media advertisement.

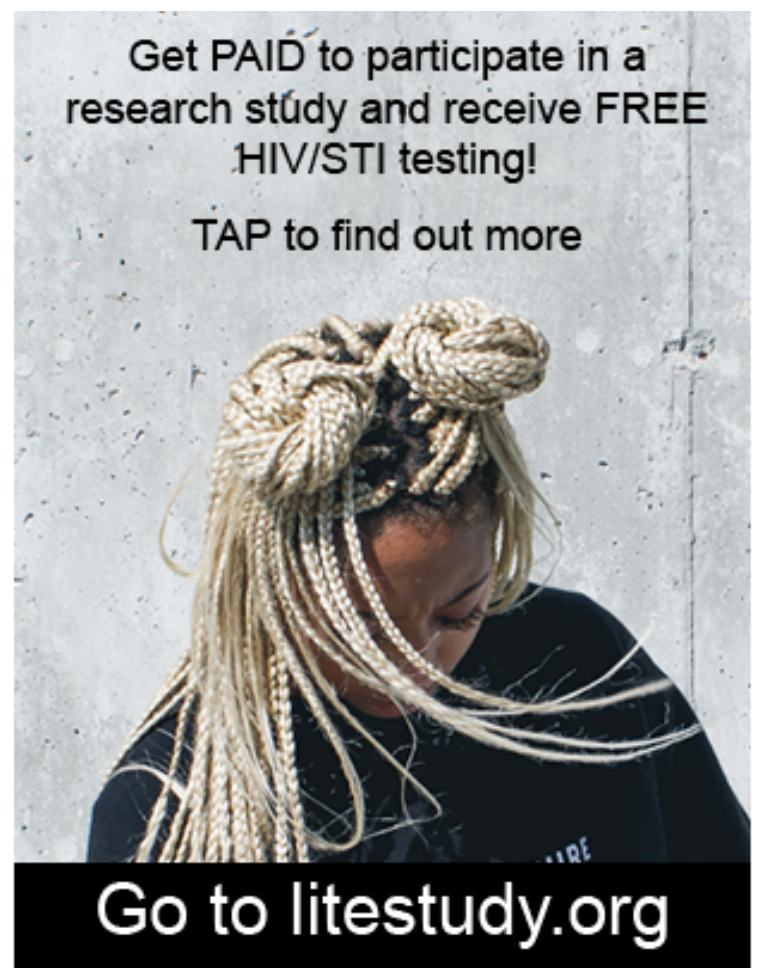

Advertisements provided a study phone number and link to the study webpage [53]. Participants who followed the link to the webpage could view study information in English or Spanish and access screening and enrollment for the online cohort. Screening assessments were automated with staff review. Individuals living in the 6 site-based cohort cities had the option to enroll in either cohort and could switch cohort at any point over the course of follow-up, depending on their location of residence.

Once a participant provided a unique email on the screening form, was determined to be eligible for the study, and consented to join the study, the system sent a unique link via email. Once this link had been accessed, a verification code was sent via text. On receipt of the text, the participant entered that code into the webpage to complete enrollment. The initial email message that went to consented participants included a link back to this validation page for later use, if a user was not able to provide a phone number at that time. If the code was validated, the user was directed to complete registration and the baseline survey.

Collected identifiers (name, mailing address, telephone number, and email address) are stored separately from the participant survey, and HIV testing data are retained until study end to prevent duplicate enrollments. Individuals using Voice Over Internet Protocol phone numbers are also prevented from enrolling to mitigate fraudulent behaviors or enrollment. An internal algorithm ran real-time checks to identify any duplicate or partially matched identifiers. Identical matches were 
prohibited from registering; partial matches were reviewed by study staff for final determination.

\section{Data Collection}

Data collection, both survey completion and specimen collection, are supported through the use of a hybrid app developed for this study. The hybrid app enables download of the secure app on Android and iOS operating systems but also provides an optional web-based platform for non-smartphone users. We elected to use a hybrid app, recognizing that while transgender women have high rates of internet use [54], reliance solely on app-based data collection may threaten study retention.

\section{Hybrid App}

The app, which was developed for the site-based cohorts, was modified for the online cohort to display the participants' study timeline and available activities, change contact information and incentive preferences, complete study surveys, request a self-collection kit for HIV testing, and report when they have sent a specimen to the laboratory (see Figure 2). Participants log into the app using a unique token that is generated at enrollment. Once the app is downloaded, participants can set their own PIN, which is required for subsequent entry to the app. All collected data are encrypted in transit from the device to the secure server, and identifying information is stored encrypted within the database using the AES 256-bit protocol. Staff with role-based access can access a dashboard to view participant study progress, enter lab results, and view contact information for shipment of specimen collection kits to participants. All components of the app and other study materials are available in the English and Spanish languages.

Figure 2. Participant view of the hybrid app of the online cohort, including (A) access to survey or HIV specimen collection kit within a study visit, (B) HIV test home kit shipping confirmation, and (C) home kit specimen collection instructions.

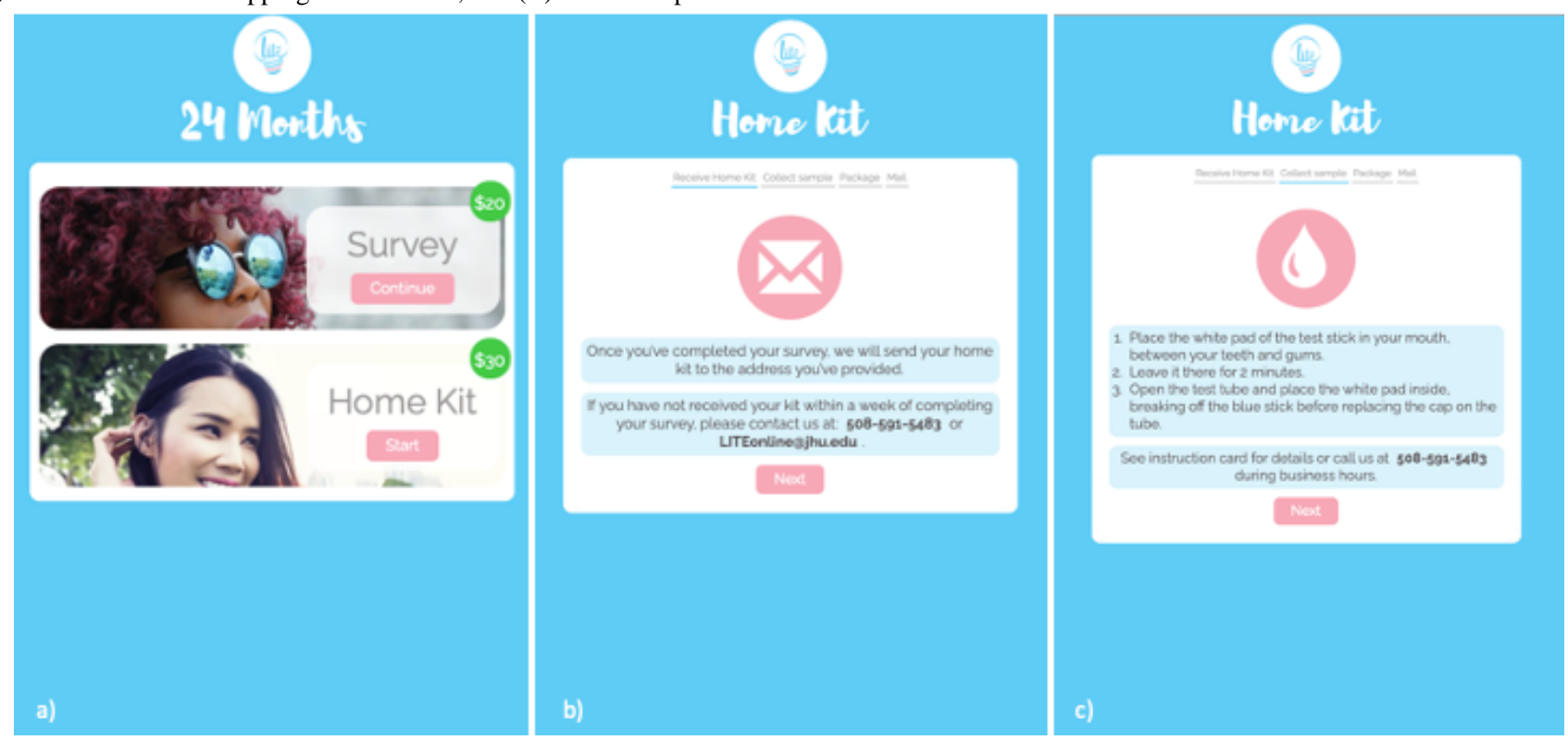

\section{Survey Measures}

All surveys are self-administered using the study hybrid app. Survey measures span domains set forth by the social ecological model [55] and by the situated vulnerabilities framework [56], including individual, interpersonal, and structural level measures. Unlike the site-based cohort, participants do not complete a literacy screener and do not have an option for staff-administered surveys, given the remote nature of data collection.

Measures have been previously described [23] but briefly include the following: individual-level measures collect data on demographics; access to and use of gender-affirming services [57]; sexual health history and access or uptake of HIV services [58]; health insurance and primary care, mental and behavioral health [59], and barriers and facilitators to care [60-62]; substance use [63-65]; gender affirmation and dysphoria [66]; and engagement in the HIVPC [67]. Interpersonal measures include social support and social network size; detailed partner-by-partner sexual behavior information by partner type and HIV status [68,69]; and measures of intimate and nonpartner physical, sexual, and psychological violence victimization [70]. Structural-level measures include social marginalization and stigma [71]; social capital [72,73]; interactions with the justice system; and measures of immigration status, citizenship, and interactions with immigration detention. As recommended by the $\mathrm{CAB}$, an additional measure of food insecurity was included in the survey [74]. To mitigate risk of incomplete surveys due to survey duration, longer scales that focused on gender pride, community connectedness, and condom use self-efficacy are not included in the online cohort survey.

At the end of the survey, information is provided to the participant about nationally available and LGBTQ-friendly locators for HIV testing, pre-exposure prophylaxis services, and LGBTQ health centers. The survey is also programmed to display locators for nationally available and LGBTQ-friendly mental health services and suicide prevention; violence services; and substance use services for individuals who report mental health symptoms, experiences of violence victimization, or substance use during the course of the survey. Both English and Spanish language resources are included, though Spanish-speaking hotlines often have more limited hours. 


\section{Biologic Measures}

Online cohort participants are asked to provide an oral fluid specimen at baseline and every 6 months for HIV testing. We elected to use oral fluid specimen collection, rather than home HIV self-testing, for 2 reasons: (1) preference to provide confirmatory testing, interactive posttest counseling, and support linkage to care for participants with positive or indeterminate preliminary results and (2) low self-reported response rates of HIV self-test results in other web-based HIV research [75,76]. Participants of the online cohort are not asked to participate in any STI testing or biospecimen storage, unlike site-based cohorts, due to resource constraints and added complexities of shipping specimens to multiple laboratories.

Specimen collection kits are sent by the study staff to the mailing address provided by the study participants. Participants are reminded to provide the name they would like shown on the package; they have the option to provide separate names for mailing vs text and email-based communication. Addresses are validated using the SmartyStreet application programming interface (API). Kits include the oral specimen collection device, OraSure, and easy-to-read bilingual information, including instructions for specimen collection with example photos, prelabeled shipping envelopes with tracking information, and a resource guide with locators for accessing HIV prevention or care resources and culturally appropriate health, mental health, substance use, and violence services.

Participants self-administer the OraSure Oral Specimen Collection Device at home in accordance with the package insert instructions [77]. The device allows for the collection of an oral fluid sample for HIV testing using a pad that is placed between the cheek and gum for 2-5 minutes. The pad is then placed into a sealable vial that contains a preservative, which stabilizes the sample for up to 21 days. Participants mail the vial and any corresponding materials to Quest Diagnostics using the prepaid label that is enclosed in the package. Participants are provided with a 24-hour OraSure Support telephone number as well as the study coordinator number if the participant has questions or difficulty using the collection device.

HIV testing is conducted at Quest Diagnostics Laboratory using an enzyme immune assay, with positive results being confirmed via western blot [78]. Confirmatory testing can take up to 6 additional days to complete. Results of the HIV tests are received by the study team within an average of 7 days. HIV test results are reviewed and provided to the participant within 48-72 hours of receipt via phone for positive results or via their preferred method of contact for negative results. The study staff review the data on a daily basis and call any participant with a positive or indeterminate test to provide posttest counseling and information about how to locate a provider in their location. All participants are informed during the consent process of the requirement to inform local health departments of positive HIV cases, which is performed by Quest Diagnostics per state requirements.

Participants who seroconvert during participation in the online cohort are asked to authorize reviews of their medical records for the purpose of collecting information on their subsequent engagement in HIV care. Participants are informed of their right to decline this request. Cohort (site-based and online) participants who seroconvert during the study will stop participation in the cohort but will be asked to complete one more study visit (in-person or online) at 3 months after the visit in which they tested positive for HIV. This visit serves to assess engagement in the HIVCC among transgender women who are newly diagnosed with HIV.

\section{Study Retention}

We use tracking and retention procedures proven effective in prior studies [23]. Study retention is operationally defined as not missing more than 2 consecutive study assessments. The hybrid app system issues automated text messages and emails to participants' devices for reminders of follow-up assessments and if study procedures are partially completed. Study staff contact participants by their preferred method (email, phone, text) if participants miss 2 consecutive study visits or regularly complete only part of the study assessment (survey or HIV specimen collection). All participants are provided with a US $\$ 50$ stipend for the completion of all study activities for each study assessment (US $\$ 20$ for survey and US $\$ 30$ for HIV test). We have elected this amount to be consistent with the in-person cohort and other research studies with transgender women in the select cities in conjunction with $\mathrm{CAB}$ input. Retention events are held remotely every few months to engage interested participants across the cohorts. Event attendance is optional, and participants can control their level of privacy, such as their displayed name and video. Events have included but are not limited to virtual trivia, film screenings, yoga, and art workshops. Virtual newsletters presenting study updates and preliminary study results across the cohorts are also shared with participants and community members on an annual basis.

\section{Sample Size}

Participants of the online cohort will contribute to the target sample size of 1100 transgender women who are not living with HIV in the LITE study. This target was based on a planned comparison of the incidence of 2 subgroups, assuming a two-sided test statistic and 5\% Type 1 error with $80 \%$ power. We conservatively estimated 700 person-years of follow-up accumulated after the first 2 years of enrollment and, incorporating a loss of $15 \%$ of follow-up time per year, we estimated we will accumulate 935 person-years, 795 person-years, and 676 person-years in years 3, 4, and 5, respectively ( $>3000$ person-years total). With this person-time, we estimated that we would have sufficient power $(80 \%)$ power to detect public health relevant differences in HIV incidence by various participant characteristics. Relative to other online cohorts $[37,39]$ and as one of the first cohorts among transgender women in the United States, we intentionally kept the sample size small to focus on developing acceptable methods and establishing trust among study participants.

\section{Analytic Plan}

Descriptive analysis will be used to compare differences in basic demographic, behavioral, and health-related characteristics among participants enrolled in the online vs the site-based cohorts, controlling for geographic region of residence. 
Qualitative differences in recruitment and retention rates will also be observed and described.

Participant data from the online cohort will also contribute to the analysis of overall LITE study, which has been previously described [23]. Briefly, these analyses will include the following: Data visualization techniques will be utilized to compare efficiency of recruitment methods in terms of process measures of time, cost, and response rates, and descriptive analyses will be conducted to compare quantitative measures of acceptability, diversity, and biases of the samples recruited via technology-enhanced and traditional recruitment methods (Aim 1). Descriptive statistics will be conducted to compare demographic and behavioral risk profiles among baseline participants, as well as to assess baseline HIVCC and HIVPC among participants living with and without HIV, respectively (Aim 2). HIV incidence (and 95\% confidence intervals) during follow-up will be estimated among the HIV-uninfected cohort (Aim 3). Poisson regression models will be used to investigate important predictors of incident infection. Time-to-event survival models will be used to estimate the risk of HIV seroconversion for the predictors. Finally, the steps in the HIVPC and HIVCC will be investigated over the course of the study using a serial cross-sectional approach to determine trends in these important frameworks (Aim 4). To make these estimates most informative for public health efforts, the steps will be estimated among those under observation in specific calendar years (ie, in 2019, 2020, and 2021).

Where relevant, we will utilize modern missing data techniques [79], with emphasis on multiple-imputation methods, which provide an approach for handling different missing data including coarsely measured [80] or mismeasured [81] variables. Adaptation of these methods to survival analyses will be similar to techniques implemented in R/MICE and SAS/IVEware [82-84]. Statistical analyses will be performed using Stata 14 (StataCorp, College Station TX) and R software (R Foundation for Statistical Computing, Vienna, Austria).

\section{Human Subjects}

Study activities follow a single institutional review board procedure and have undergone review and approval by the Johns Hopkins School of Medicine Institutional Review Board, with reliance by all collaborating organizations and institutions. Protection of participant privacy and confidentiality are central to the development and implementation of all study activities and have been further developed in discussions with the study CAB. The electronic data system has been developed with careful attention to security, including password protection and encrypted data transmission.

\section{Results}

In January 2019, we launched the online cohort in 25 cities, then expanded in April 2019 to a total of 72 cities in eastern and southern United States. In May 2019, we ended online advertisements, though eligible individuals who had heard of the study from other participants could continue to enroll. Enrollment closed in August 2020, at which point 580 participants were fully enrolled in the online cohort. We observed a recruitment-enrollment cascade in the study implementation process with successive and decreasing rates from online screening through enrollment in the online cohort: 2387 individuals were screened, 1092 individuals consented, 971 individuals completed the survey, 586 individuals completed both the HIV test and survey, and 580 individuals enrolled in the cohort (Figure 3). Ultimately, 45.7\% (1092/2387) of those screened were consented, and 53.3\% (580/1092) of those consented completed both baseline study activities for full enrollment in the cohort. The self-administered screening form effectively identified ineligible participants on the basis of HIV status, minimizing HIV testing costs, where only 4 participants were newly identified with HIV infection through baseline HIV testing procedures. Discussions with these participants determined that 3 of the 4 were newly diagnosed with HIV, and staff were able to provide appropriate counseling and referral to HIV care for these participants.

Figure 3. Recruitment-enrollment cascade: progression from screening to enrollment of an online cohort of transgender women.

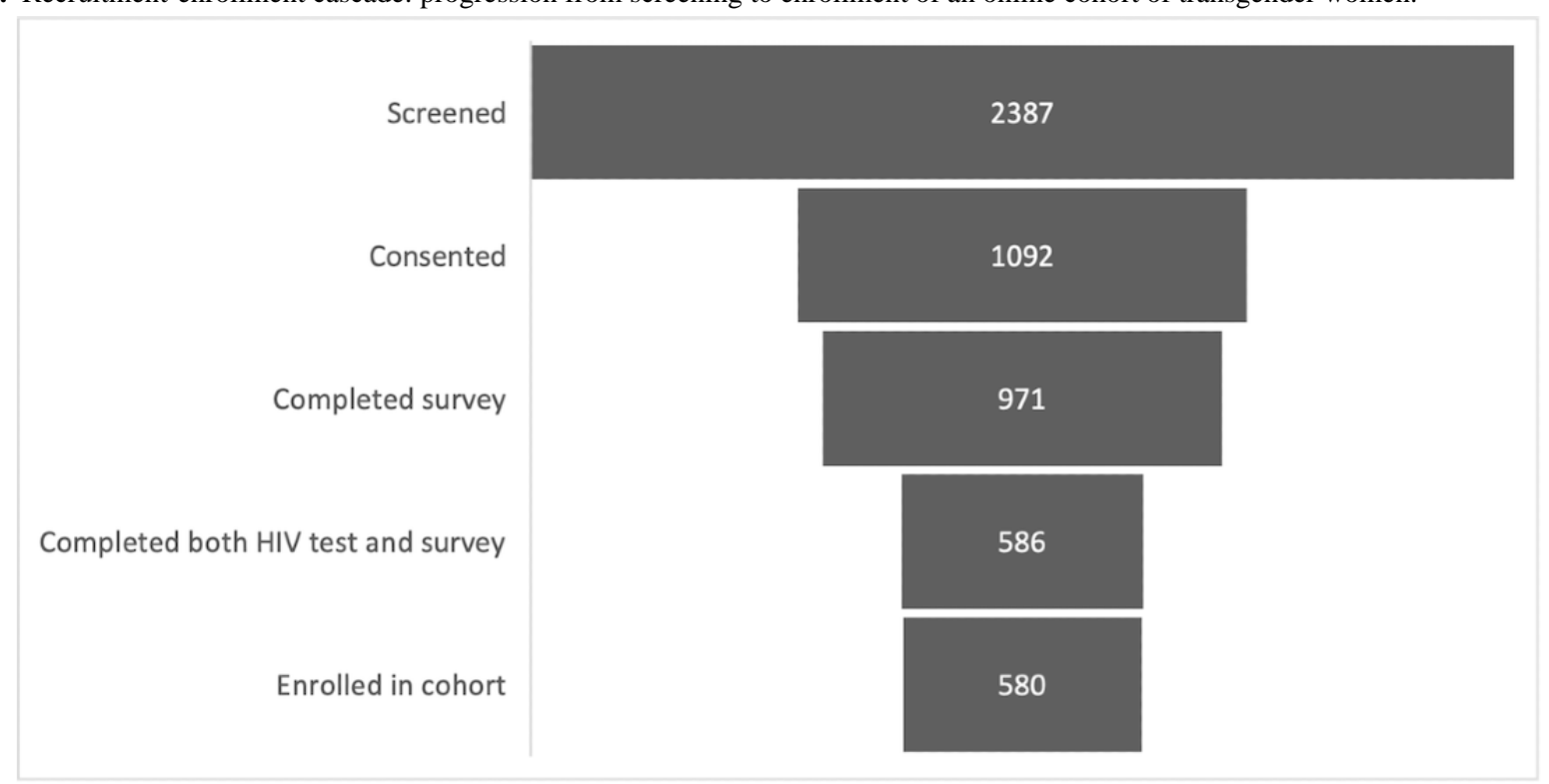


Figure 4 displays cumulative enrollment over time into the online cohort. Over one-third $(213 / 580,36.8 \%)$ of the online sample were aged 18-24 years at enrollment, and one-fifth $(125 / 580,21.6 \%)$ identify as Black, Latinx, or multiracial. Across site-based and online cohorts, we have enrolled and follow 1312 transgender women at risk for HIV in eastern and southern United States. As of the end of October 2020, 573 person-years have been contributed to the analytic dataset of the online cohort. Cohort participants are under follow-up through 2022.

Figure 4. Cumulative number of enrolled participants in the LITE online cohort.

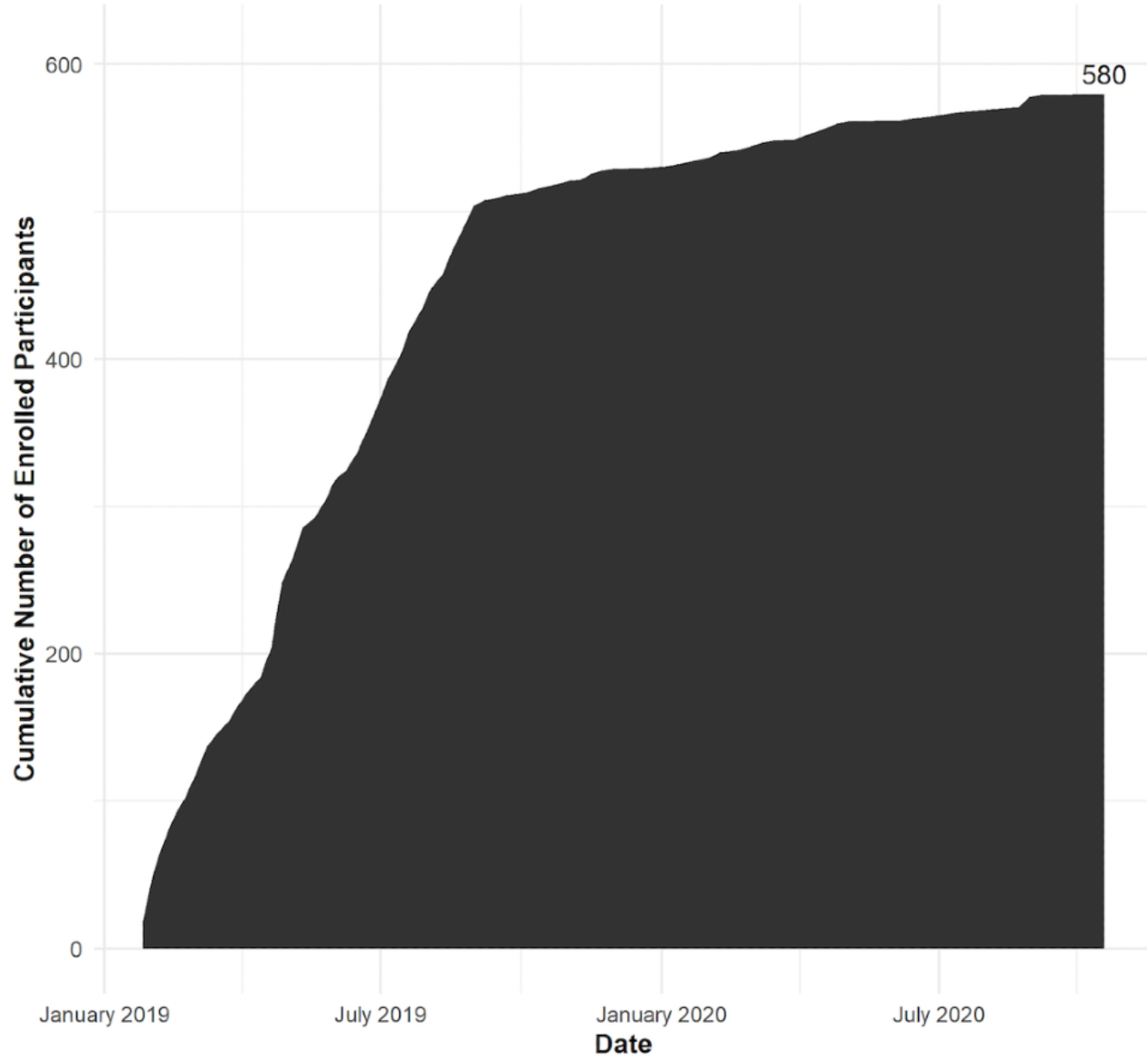

Internal shipping procedures for specimen collection kits have also led to observations of high mobility or unstable housing among cohort participants when specimen collection kits are returned by mail. While requiring more staff effort, returned packages offer an opportunity to identify address changes and connect with participants to support retention. Returned specimen collection kits during enrollment also supported identification of some fraudulent enrollments.

\section{Discussion}

This paper describes the protocol for the development and implementation of an online cohort for assessment of HIV risks and predictors of HIV acquisition among transgender women. In conjunction with the LITE site-based cohort, this study aims to inform priorities and programs of the Ending the HIV Epidemic Strategy for the United States [1,2] and innovates in its use of technology to engage and assess HIV risk among transgender women. Study findings will have important implications for identification of optimal recruitment, retention, and data collection methods for future observational research and digital or hybridized digital clinical trials among transgender women living with and without HIV infection, estimation of HIV incidence, and ultimately the development of acceptable HIV prevention strategies for ending the HIV epidemic among transgender women in the United States. As with other online cohorts and cross-sectional studies [37,39,75], we noted a recruitment-enrollment cascade from screening through enrollment and completion of study activities, which has important design, budgetary, and logistical implications for future digital epidemiologic studies and clinical trials.

This online cohort is strengthened by extensive formative research and early experiences incorporating technology-enhanced methods into the site-based cohorts $[22,23,47,48]$. Though we make every effort to ensure that technology-enhanced and digital methods are accessible, there is a risk that individuals with extremely limited access to technology may be excluded from this online cohort. Thus, the rare ability to compare study findings across site-based and online cohorts provides invaluable information about sources of bias, but more importantly indicates if use of digital methods risks excluding subgroups who could most benefit from HIV research and subsequent HIV prevention and care interventions. 


\section{Acknowledgments}

The authors would like to express their gratitude to the transgender women who take part in this study. This study would not be possible without their participation. We appreciate the continued involvement and contributions by the CAB that supports and guides this study. Research reported in this publication was jointly supported by the National Institute of Allergy and Infectious Diseases, National Institute of Mental Health, and National Institute of Child Health and Human Development of the National Institutes of Health under Award Number UG3/UH3AI133669 (Wirtz/Reisner). Research reported in this publication was also supported by HIV/AIDS, Hepatitis, STD, and TB Administration (HAHSTA), Washington DC Department of Health. The LITE study is also appreciative of support from the CFAR at partner institutions, including JHU (P30AI094189), Emory University (P30AI050409), Harvard University (P30AI060354), DC CFAR (AI117970), and the University of Miami (P30AI073961). The content is solely the responsibility of the authors and does not necessarily represent the official views of the National Institutes of Health or HAHSTA.

\section{Authors' Contributions}

The following are members of the collaborative author, American Cohort to Study HIV Acquisition Among Transgender Women (also known as the LITE cohort): Sari Reisner (multiple principal investigator [PI]; Harvard University, Brigham and Women's Hospital); Andrea Wirtz (multiple PI; Johns Hopkins University [JHU]); Keri Althoff (JHU); Chris Beyrer (JHU); James Case (JHU); Erin Cooney (JHU); Oliver Laeyendecker (JHU); Tonia Poteat (University of North Carolina); Ken Mayer (Fenway Health); Asa Radix (Callen-Lorde Community Health Center); Christopher M Cannon (Whitman-Walker Institute); Jason Schneider (Emory University and Grady Hospital); J. Sonya Haw (Emory University and Grady Hospital); Allan Rodriguez (University of Miami); Andrew Wawrzyniak (University of Miami); and the LITE CAB, including Sherri Meeks, Sydney Shackelford, Nala Toussaint, SaVanna Wanzer, as well as those who have remained anonymous. ALW and SLR developed the study concept; TP, AR, KNA, CC, AW, EC, and KM provided extensive input to the original grant submission and/or the protocol manuscript; ALW wrote the first draft of the manuscript; MS coordinates the online cohort; and all authors reviewed and provided scientific input to the manuscript.

\section{Conflicts of Interest}

KNA serves as a consultant to the All of Study (NIH) and on the scientific advisory board for TrioHealth Inc.

\section{References}

1. Fauci AS, Redfield RR, Sigounas G, Weahkee MD, Giroir BP. Ending the HIV Epidemic: A Plan for the United States. JAMA 2019 Mar 05;321(9):844-845. [doi: 10.1001/jama.2019.1343] [Medline: 30730529]

2. HIV National Strategic Plan: A Roadmap to End the Epidemic (2021-2025). U.S. Department of Health \& Human Services. URL: https://www.hiv.gov/federal-response/hiv-national-strategic-plan/hiv-plan-2021-2025 [accessed 2021-04-05]

3. Grant J, Mottet L, Tanis J, Harrison J, Herman J, Keisling M. Injustice at Every Turn: A Report of the National Transgender Discrimination Survey. Washington, DC: National Center for Transgender Equality and National Gay and Lesbian Task Force; 2011. URL: https://www.transequality.org/sites/default/files/docs/resources/NTDS Report.pdf [accessed 2021-04-05]

4. Xavier JM, Bobbin M, Singer B, Budd E. A Needs Assessment of Transgendered People of Color Living in Washington, DC. International Journal of Transgenderism 2005 Oct 11;8(2-3):31-47. [doi: 10.1300/j485v08n02 04]

5. Towe V, Ayer L, Sellers C, Saracco E, McMillan D, Clay C. HIV Risk among Transgender and Non-Transgender Sex Workers in DC. 2013 Presented at: Transgender Health Summit; May 2013; Philadelphia, PA.

6. Elifson KW, Boles J, Posey E, Sweat M, Darrow W, Elsea W. Male transvestite prostitutes and HIV risk. Am J Public Health 1993 Feb;83(2):260-262. [doi: 10.2105/ajph.83.2.260] [Medline: 8427336]

7. Boles J, Elifson KW. The social organization of transvestite prostitution and AIDS. Social Science \& Medicine 1994 Jul;39(1):85-93. [doi: 10.1016/0277-9536(94)90168-6] [Medline: $\underline{8066491]}$

8. Wilson EC, Garofalo R, Harris DR, Belzer M. Sexual risk taking among transgender male-to-female youths with different partner types. Am J Public Health 2010 Aug;100(8):1500-1505 [FREE Full text] [doi: 10.2105/AJPH.2009.160051] [Medline: 20622176]

9. Wilson EC, Garofalo R, Harris RD, Herrick A, Martinez M, Martinez J, Transgender Advisory Committee of the Adolescent Medicine Trials Network for HIV/AIDS Interventions. Transgender female youth and sex work: HIV risk and a comparison of life factors related to engagement in sex work. AIDS Behav 2009 Oct;13(5):902-913 [FREE Full text] [doi: 10.1007/s10461-008-9508-8] [Medline: 19199022]

10. Lombardi EL, Wilchins RA, Priesing D, Malouf D. Gender violence: transgender experiences with violence and discrimination. J Homosex 2001;42(1):89-101. [doi: 10.1300/j082v42n01 05] [Medline: 11991568 ]

11. Sanchez T, Finlayson T, Murrill C, Guilin V, Dean L. Risk behaviors and psychosocial stressors in the new york city house ball community: a comparison of men and transgender women who have sex with men. AIDS Behav $2010 \mathrm{Apr}$ 10;14(2):351-358. [doi: 10.1007/s10461-009-9610-6] [Medline: 19763812] 
12. Wirtz AL, Poteat TC, Malik M, Glass N. Gender-Based Violence Against Transgender People in the United States: A Call for Research and Programming. Trauma Violence Abuse 2020 Apr 13;21(2):227-241. [doi: 10.1177/1524838018757749] [Medline: 29439615]

13. Becasen JS, Denard CL, Mullins MM, Higa DH, Sipe TA. Estimating the Prevalence of HIV and Sexual Behaviors Among the US Transgender Population: A Systematic Review and Meta-Analysis, 2006-2017. Am J Public Health 2019 Jan;109(1):e1-e8. [doi: 10.2105/ajph.2018.304727]

14. Sevelius JM, Patouhas E, Keatley JG, Johnson MO. Barriers and facilitators to engagement and retention in care among transgender women living with human immunodeficiency virus. Ann Behav Med 2014 Feb 7;47(1):5-16 [FREE Full text] [doi: 10.1007/s12160-013-9565-8] [Medline: 24317955]

15. Poteat T, Reisner SL, Radix A. HIV epidemics among transgender women. Curr Opin HIV AIDS 2014 Mar;9(2):168-173 [FREE Full text] [doi: 10.1097/COH.0000000000000030] [Medline: 24322537]

16. Deutsch MB, Glidden DV, Sevelius J, Keatley J, McMahan V, Guanira J, et al. HIV pre-exposure prophylaxis in transgender women: a subgroup analysis of the iPrEx trial. The Lancet HIV 2015 Dec;2(12):e512-e519. [doi: 10.1016/S2352-3018(15)00206-4]

17. Castillo R, Konda KA, Leon SR, Silva-Santisteban A, Salazar X, Klausner JD, et al. HIV and Sexually Transmitted Infection Incidence and Associated Risk Factors Among High-Risk MSM and Male-to-Female Transgender Women in Lima, Peru. J Acquir Immune Defic Syndr 2015 Aug 15;69(5):567-575 [FREE Full text] [doi: 10.1097/QAI.0000000000000667] [Medline: 25950207]

18. Castillo-Chavez C, Cooke K, Huang W, Levin S. Results on the dynamics for models for the sexual transmission of the human immunodeficiency virus. Applied Mathematics Letters 1989;2(4):327-331. [doi: 10.1016/0893-9659(89)90080-3]

19. Reisner SL, Moore CS, Asquith A, Pardee DJ, Mayer KH. Gender Non-affirmation from Cisgender Male Partners: Development and Validation of a Brief Stigma Scale for HIV Research with Transgender Men Who Have Sex with Men (Trans MSM). AIDS Behav 2020 Jan;24(1):331-343. [doi: 10.1007/s10461-019-02749-5] [Medline: $\underline{31865515]}$

20. Reisner SL, Moore CS, Asquith A, Pardee DJ, Sarvet A, Mayer G, et al. High risk and low uptake of pre-exposure prophylaxis to prevent HIV acquisition in a national online sample of transgender men who have sex with men in the United States. J Int AIDS Soc 2019 Sep;22(9):e25391 [FREE Full text] [doi: 10.1002/jia2.25391] [Medline: $\underline{31536171]}$

21. Reisner SL, Murchison GR. A global research synthesis of HIV and STI biobehavioural risks in female-to-male transgender adults. Glob Public Health 2016 Jan 20;11(7-8):866-887 [FREE Full text] [doi: 10.1080/17441692.2015.1134613] [Medline: 26785800]

22. Reisner SL, Chaudhry A, Cooney E, Garrison-Desany H, Juarez-Chavez E, Wirtz AL. 'It all dials back to safety': A qualitative study of social and economic vulnerabilities among transgender women participating in HIV research in the USA. BMJ Open 2020 Jan 19;10(1):e029852 [FREE Full text] [doi: 10.1136/bmjopen-2019-029852] [Medline: $\underline{31959600]}$

23. Wirtz AL, Poteat T, Radix A, Althoff KN, Cannon CM, Wawrzyniak AJ, American Cohort To Study HIV Acquisition Among Transgender Women (LITE). American Cohort to Study HIV Acquisition Among Transgender Women in High-Risk Areas (The LITE Study): Protocol for a Multisite Prospective Cohort Study in the Eastern and Southern United States. JMIR Res Protoc 2019 Oct 03;8(10):e14704 [FREE Full text] [doi: 10.2196/14704] [Medline: 31584005]

24. All of Us Research Program Overview. National Institutes of Health. URL: https://allofus.nih.gov/about/ about-all-us-research-program [accessed 2021-04-05]

25. Black Women's Health Study. Boston University Slone Epidemiology Center. URL: https://www.bu.edu/bwhs/history/ [accessed 2021-04-05]

26. Goedel WC, Duncan DT. Geosocial-Networking App Usage Patterns of Gay, Bisexual, and Other Men Who Have Sex With Men: Survey Among Users of Grindr, A Mobile Dating App. JMIR Public Health Surveill 2015;1(1):e4 [FREE Full text] [doi: 10.2196/publichealth.4353] [Medline: 27227127]

27. Arrington-Sanders R, Hailey-Fair K, Wirtz A, Cos T, Galai N, Brooks D, PUSH Study Team. Providing Unique Support for Health Study Among Young Black and Latinx Men Who Have Sex With Men and Young Black and Latinx Transgender Women Living in 3 Urban Cities in the United States: Protocol for a Coach-Based Mobile-Enhanced Randomized Control Trial. JMIR Res Protoc 2020 Sep 16;9(9):e17269 [FREE Full text] [doi: 10.2196/17269] [Medline: $\underline{32935662]}$

28. Drake AL, Rothschild C, Jiang W, Ronen K, Unger JA. Utility of Short Message Service (SMS) for Remote Data Collection for HIV in Low- and Middle-Income Countries. Curr HIV/AIDS Rep 2020 Dec;17(6):654-662 [FREE Full text] [doi: 10.1007/s11904-020-00534-x] [Medline: 33010003]

29. Wirtz AL, Weir BW, Mon SHH, Sirivongrangson P, Chemnasiri T, Dunne EF, Combination Prevention Effectiveness (COPE) Study Team. Testing the Effectiveness and Cost-Effectiveness of a Combination HIV Prevention Intervention Among Young Cisgender Men Who Have Sex With Men and Transgender Women Who Sell or Exchange Sex in Thailand: Protocol for the Combination Prevention Effectiveness Study. JMIR Res Protoc 2020 Jan 27;9(1):e15354 [FREE Full text] [doi: 10.2196/15354] [Medline: 32012113]

30. Rosenberg ES, Rothenberg RB, Kleinbaum DG, Stephenson RB, Sullivan PS. Assessment of a new web-based sexual concurrency measurement tool for men who have sex with men. J Med Internet Res 2014 Nov 10;16(11):e246 [FREE Full text] [doi: 10.2196/jmir.3211] [Medline: 25386801] 
31. Platteau T, Fransen K, Apers L, Kenyon C, Albers L, Vermoesen T, et al. Swab2know: An HIV-Testing Strategy Using Oral Fluid Samples and Online Communication of Test Results for Men Who Have Sex With Men in Belgium. J Med Internet Res 2015 Sep 01;17(9):e213 [FRE Full text] [doi: 10.2196/jmir.4384] [Medline: 26330138]

32. Siegler AJ, Mayer KH, Liu AY, Patel RR, Ahlschlager LM, Kraft CS, et al. Developing and Assessing the Feasibility of a Home-based Preexposure Prophylaxis Monitoring and Support Program. Clin Infect Dis 2019 Jan 18;68(3):501-504 [FREE Full text] [doi: 10.1093/cid/ciy529] [Medline: 29982304]

33. Andriesen J, Bull S, Dietrich J, Haberer JE, Van Der Pol B, Voronin Y, et al. Using Digital Technologies in Clinical HIV Research: Real-World Applications and Considerations for Future Work. J Med Internet Res 2017 Jul 31;19(7):e274 [FREE Full text] [doi: 10.2196/jmir.7513] [Medline: 28760729]

34. Hickson F, Tomlin K, Hargreaves J, Bonell C, Reid D, Weatherburn P. Internet-based cohort study of HIV testing over 1 year among men who have sex with men living in England and exposed to a social marketing intervention promoting testing. Sex Transm Infect 2015 Feb;91(1):24-30. [doi: 10.1136/sextrans-2014-051598] [Medline: 25270006]

35. Cheung DH, Suharlim C, Guadamuz TE, Lim SH, Koe S, Wei C. Earlier anal sexarche and co-occurring sexual risk are associated with current HIV-related risk behaviors among an online sample of men who have sex with men in Asia. AIDS Behav 2014 Dec;18(12):2423-2431 [FRE Full text] [doi: 10.1007/s10461-014-0821-0] [Medline: 24920344]

36. Matthews JE, Stephenson R, Sullivan PS. Factors associated with self-reported HBV vaccination among HIV-negative MSM participating in an online sexual health survey: a cross-sectional study. PLoS One 2012;7(2):e30609 [FREE Full text] [doi: 10.1371/journal.pone.0030609] [Medline: 22363453]

37. Nash D, Stief M, MacCrate C, Mirzayi C, Patel VV, Hoover D, et al. A Web-Based Study of HIV Prevention in the Era of Pre-Exposure Prophylaxis Among Vulnerable HIV-Negative Gay and Bisexual Men, Transmen, and Transwomen Who Have Sex With Men: Protocol for an Observational Cohort Study. JMIR Res Protoc 2019 Sep 17;8(9):e13715 [FREE Full text] [doi: 10.2196/13715] [Medline: 31538945]

38. Serrano PA, Daubert E, Munoz A, Hosek SG, French AL. Effect of Truvada lawsuit advertising on preexposure prophylaxis attitudes and decisions among sexual and gender minority youth and young adults at risk for HIV. AIDS 2021 Jan 01;35(1):131-139. [doi: 10.1097/QAD.0000000000002728] [Medline: 33031102]

39. Rendina HJ, Talan AJ, Tavella NF, Matos JL, Jimenez RH, Jones SS, et al. Leveraging Technology to Blend Large-Scale Epidemiologic Surveillance with Social and Behavioral Science Methods: Successes, Challenges, and Lessons Learned Implementing the UNITE Longitudinal Cohort Study of HIV risk factors among Sexual Minority Men in the U.S. Am J Epidemiol 2020 Oct 15:1. [doi: 10.1093/aje/kwaa226] [Medline: 33057684]

40. Bauermeister JA, Pingel ES, Jadwin-Cakmak L, Harper GW, Horvath K, Weiss G, et al. Acceptability and preliminary efficacy of a tailored online HIV/STI testing intervention for young men who have sex with men: the Get Connected! program. AIDS Behav 2015 Oct 1;19(10):1860-1874 [FREE Full text] [doi: 10.1007/s 10461-015-1009-y] [Medline: 25638038]

41. Villegas N, Santisteban D, Cianelli R, Ferrer L, Ambrosia T, Peragallo N, et al. Pilot testing an internet-based STI and HIV prevention intervention with Chilean women. J Nurs Scholarsh 2015 Mar;47(2):106-116 [FREE Full text] [doi: 10.1111/jnu.12114] [Medline: 25410132]

42. Catalani C, Philbrick W, Fraser H, Mechael P, Israelski DM. Open AIDS J 2013;7:17-41 [FREE Full text] [doi: 10.2174/1874613620130812003] [Medline: 24133558]

43. Anderson-Lewis C, Darville G, Mercado RE, Howell S, Di Maggio S. mHealth Technology Use and Implications in Historically Underserved and Minority Populations in the United States: Systematic Literature Review. JMIR Mhealth Uhealth 2018 Jun 18;6(6):e128 [FREE Full text] [doi: 10.2196/mhealth.8383] [Medline: 29914860]

44. Arayasirikul S, Turner C, Trujillo D, Le V, Beltran T, Wilson EC. Does the Use of Motivational Interviewing Skills Promote Change Talk Among Young People Living With HIV in a Digital HIV Care Navigation Text Messaging Intervention? Health Promot Pract 2020 Sep;21(5):738-743. [doi: 10.1177/1524839920936246] [Medline: 32757836]

45. Muessig KE, Pike EC, Legrand S, Hightow-Weidman LB. Mobile phone applications for the care and prevention of HIV and other sexually transmitted diseases: a review. J Med Internet Res 2013 Jan 04;15(1):e1 [FREE Full text] [doi: 10.2196/jmir.2301] [Medline: 23291245]

46. Enah C, Moneyham L, Vance DE, Childs G. Digital gaming for HIV prevention with young adolescents. J Assoc Nurses AIDS Care 2013;24(1):71-80. [doi: 10.1016/j.jana.2012.03.005] [Medline: 22871481]

47. Wirtz AL, Cooney EE, Chaudhry A, Reisner SL, American Cohort To Study HIV Acquisition Among Transgender Women. Computer-Mediated Communication to Facilitate Synchronous Online Focus Group Discussions: Feasibility Study for Qualitative HIV Research Among Transgender Women Across the United States. J Med Internet Res 2019 Mar 29;21(3):e12569 [FREE Full text] [doi: 10.2196/12569] [Medline: 30924782]

48. Akinola M, Wirtz AL, Chaudhry A, Cooney E, Reisner SL, American Cohort to Study HIV Acquisition Among Transgender Women. Perceived acceptability and feasibility of HIV self-testing and app-based data collection for HIV prevention research with transgender women in the United States. AIDS Care 2021 Jan 23:1-9. [doi: 10.1080/09540121.2021.1874269] [Medline: 33487032]

49. Quinn SC. Ethics in public health research: protecting human subjects: the role of community advisory boards. Am J Public Health 2004 Jun;94(6):918-922. [doi: 10.2105/ajph.94.6.918] [Medline: 15249289] 
50. Strauss RP, Sengupta S, Quinn SC, Goeppinger J, Spaulding C, Kegeles SM, et al. The role of community advisory boards: involving communities in the informed consent process. Am J Public Health 2001 Dec;91(12):1938-1943. [doi: 10.2105/ajph.91.12.1938] [Medline: 11726369 ]

51. Sausa L, Sevelius J, Keatley J, Iniguez J, Reyes M. Policy recommendations for inclusive data collection of trans people in HIV prevention, care \& services. San Francisco, CA: Center of Excellence for Transgender HIV Prevention, University of California; 2009.

52. Tate CC, Ledbetter JN, Youssef CP. A two-question method for assessing gender categories in the social and medical sciences. J Sex Res 2013;50(8):767-776. [doi: 10.1080/00224499.2012.690110] [Medline: 22989000]

53. Leading Innovation for Transgender Women's Health and Empowerment: The LITE Study. 2018. URL: www.litestudy. org [accessed 2021-04-05]

54. Patel VV, Masyukova M, Sutton D, Horvath KJ. Social Media Use and HIV-Related Risk Behaviors in Young Black and Latino Gay and Bi Men and Transgender Individuals in New York City: Implications for Online Interventions. J Urban Health 2016 Apr;93(2):388-399 [FREE Full text] [doi: 10.1007/s11524-016-0025-1] [Medline: 26936854]

55. Baral S, Logie CH, Grosso A, Wirtz AL, Beyrer C. Modified social ecological model: a tool to guide the assessment of the risks and risk contexts of HIV epidemics. BMC Public Health 2013 May 17;13:482 [FREE Full text] [doi: 10.1186/1471-2458-13-482] [Medline: 23679953]

56. Reisner SL, Poteat T, Keatley J, Cabral M, Mothopeng T, Dunham E, et al. Global health burden and needs of transgender populations: a review. Lancet 2016 Jul 23;388(10042):412-436 [FREE Full text] [doi: 10.1016/S0140-6736(16)00684-X] [Medline: 27323919]

57. Meyer I, Bockting W, Herman J, Reisner S. TransPop Study. 2016. URL: http://www.transpop.org/ [accessed 2021-04-05]

58. MacKellar DA, Gallagher KM, Finlayson T, Sanchez T, Lansky A, Sullivan PS. Surveillance of HIV risk and prevention behaviors of men who have sex with men--a national application of venue-based, time-space sampling. Public Health Rep 2007;122 Suppl 1:39-47 [FREE Full text] [doi: 10.1177/00333549071220S107] [Medline: 17354526]

59. Sheehan DV, Lecrubier Y, Sheehan KH, Amorim P, Janavs J, Weiller E, et al. The Mini-International Neuropsychiatric Interview (M.I.N.I.): the development and validation of a structured diagnostic psychiatric interview for DSM-IV and ICD-10. J Clin Psychiatry 1998;59 Suppl 20:22-33;quiz 34. [Medline: 9881538]

60. Radix AE, Lelutiu-Weinberger C, Gamarel KE. Satisfaction and Healthcare Utilization of Transgender and Gender Non-Conforming Individuals in NYC: A Community-Based Participatory Study. LGBT Health 2014 Dec;1(4):302-308. [doi: 10.1089/lgbt.2013.0042] [Medline: 26789858]

61. Reisner SL, Radix A, Deutsch MB. Integrated and Gender-Affirming Transgender Clinical Care and Research. J Acquir Immune Defic Syndr 2016 Aug 15;72 Suppl 3:S235-S242 [FREE Full text] [doi: 10.1097/QAI.0000000000001088] [Medline: 27429189]

62. Safer JD, Coleman E, Feldman J, Garofalo R, Hembree W, Radix A, et al. Barriers to healthcare for transgender individuals. Curr Opin Endocrinol Diabetes Obes 2016 Apr;23(2):168-171 [FREE Full text] [doi: 10.1097/MED.0000000000000227] [Medline: 26910276]

63. Skinner HA. The drug abuse screening test. Addict Behav 1982;7(4):363-371. [doi: 10.1016/0306-4603(82)90005-3] [Medline: 7183189]

64. Kalichman S, Eaton L, Cherry C, Kalichman M, Pope H, White D, et al. HIV super-infection beliefs and sexual practices of people living with HIV/AIDS. Sex Health 2010 Dec;7(4):420-424 [FREE Full text] [doi: 10.1071/SH09121] [Medline: 21062581]

65. Saunders J, Aasland O, Babor T, de la Fuente JR, Grant M. Development of the Alcohol Use Disorders Identification Test (AUDIT): WHO Collaborative Project on Early Detection of Persons with Harmful Alcohol Consumption--II. Addiction 1993 Jun;88(6):791-804. [doi: 10.1111/j.1360-0443.1993.tb02093.x] [Medline: 8329970]

66. Sjoberg M, Walch S, Stanny C. Development and Initial Psychometric Evaluation of the Transgender Adaptation and Integration Measure (TG AIM). International Journal of Transgenderism 2006 Jun;9(2):35-45. [doi: 10.1300/J485v09n02 05]

67. McNairy ML, El-Sadr WM. A paradigm shift: focus on the HIV prevention continuum. Clin Infect Dis 2014 Jul;59 Suppl 1:S12-S15 [FREE Full text] [doi: 10.1093/cid/ciu251] [Medline: 24926026]

68. Donenberg GR, Emerson E, Bryant FB, Wilson H, Weber-Shifrin E. Understanding AIDS-risk behavior among adolescents in psychiatric care: links to psychopathology and peer relationships. J Am Acad Child Adolesc Psychiatry 2001 Jun;40(6):642-653 [FREE Full text] [doi: 10.1097/00004583-200106000-00008] [Medline: 11392341]

69. Kuhns LM, Mimiaga MJ, Reisner SL, Biello K, Garofalo R. Project LifeSkills - a randomized controlled efficacy trial of a culturally tailored, empowerment-based, and group-delivered HIV prevention intervention for young transgender women: study protocol. BMC Public Health 2017 Sep 16;17(1):713 [FREE Full text] [doi: 10.1186/s12889-017-4734-5] [Medline: $\underline{28915919]}$

70. WHO multi-country study on women's health and domestic violence against women. World Health Organization. 2005. URL: https://www.who.int/reproductivehealth/publications/violence/24159358X/en/ [accessed 2021-04-05]

71. Scheim A, Bauer G. The Intersectional Discrimination Index: Development and validation of measures of self-reported enacted and anticipated discrimination for intercategorical analysis. Soc Sci Med 2019 Apr;226:225-235 [FREE Full text] [doi: $\underline{10.1016 / j . s o c s c i m e d .2018 .12 .016}$ ] [Medline: $\underline{\text { 30674436] }] ~}$ 
72. Onyx J, Bullen P. Measuring Social Capital in Five Communities. The Journal of Applied Behavioral Science 2016 Jul 26;36(1):23-42. [doi: 10.1177/0021886300361002]

73. Webel A, Phillips JC, Rose CD, Holzemer WL, Chen W, Tyer-Viola L, et al. A cross-sectional description of social capital in an international sample of persons living with HIV/AIDS (PLWH). BMC Public Health 2012 Mar 13;12(1):188 [FREE Full text] [doi: 10.1186/1471-2458-12-188] [Medline: 22414342]

74. U.S. Household Food Security Survey Module: Three-Stage Design, With Screeners. Economic Research Service, USDA. 2012 Sep. URL: https://www.ers.usda.gov/media/8271/hh2012.pdf [accessed 2021-04-05]

75. De Boni RB, Veloso VG, Fernandes NM, Lessa F, Corrêa RG, Lima RDS, et al. An Internet-Based HIV Self-Testing Program to Increase HIV Testing Uptake Among Men Who Have Sex With Men in Brazil: Descriptive Cross-Sectional Analysis. J Med Internet Res 2019 Aug 01;21(8):e14145 [FREE Full text] [doi: 10.2196/14145] [Medline: 31373276]

76. Huang E, Marlin RW, Young SD, Medline A, Klausner JD. Using Grindr, a Smartphone Social-Networking Application, to Increase HIV Self-Testing Among Black and Latino Men Who Have Sex With Men in Los Angeles, 2014. AIDS Educ Prev 2016 Aug;28(4):341-350 [FREE Full text] [doi: 10.1521/aeap.2016.28.4.341] [Medline: 27427928]

77. OraSure ${ }^{\circledR}$ HIV-1 Oral Specimen Collection Device. OraSure Technologies. URL: https://www.orasure.com/ products-infectious/OSCD-HIV.html [accessed 2021-04-05]

78. Holmström P, Syrjänen S, Laine P, Valle SL, Suni J. HIV antibodies in whole saliva detected by ELISA and western blot assays. J Med Virol 1990 Apr;30(4):245-248. [doi: 10.1002/jmv.1890300403] [Medline: 2370520]

79. Little RJA, Rubin DB. Statistical Analysis with Missing Data. New York City, NY: Wiley-Interscience; Sep $09,2002$.

80. Heitjan D, Rubin D. Inference from Coarse Data Via Multiple Imputation with Application to Age Heaping. Journal of the American Statistical Association 1990 Jun;85(410):304-314. [doi: 10.2307/2289765]

81. Cole SR, Chu H, Greenland S. Multiple-imputation for measurement-error correction. Int J Epidemiol 2006 Aug;35(4):1074-1081. [doi: 10.1093/ije/dyl097] [Medline: 16709616]

82. Raghunathan T, Lepkowski J, Van HJ, Solenberger P. A multivariate technique for multiply imputing missing values using a sequence of regression models. Survey methodology 2001;27(1):85-96 [FREE Full text]

83. Raghunathan T, Solenberger PW, Hoewyk JV. IVEware: Imputation and variance estimation software. 2007. Ann Arbor, MI: Survey Methodology Program, Survey Research Center, Institute for Social Research, University of Michigan; 2007.

84. Stuart EA, Azur M, Frangakis C, Leaf P. Multiple imputation with large data sets: a case study of the Children's Mental Health Initiative. Am J Epidemiol 2009 May 01;169(9):1133-1139 [FREE Full text] [doi: 10.1093/aje/kwp026] [Medline: $\underline{19318618}]$

\section{Abbreviations}

API: application programming interface

CAB: community advisory board

HIVCC: HIV Care Continuum

HIVPC: HIV Prevention Continuum

JHU: Johns Hopkins University

PI: principal investigator

STI: sexually transmitted infection

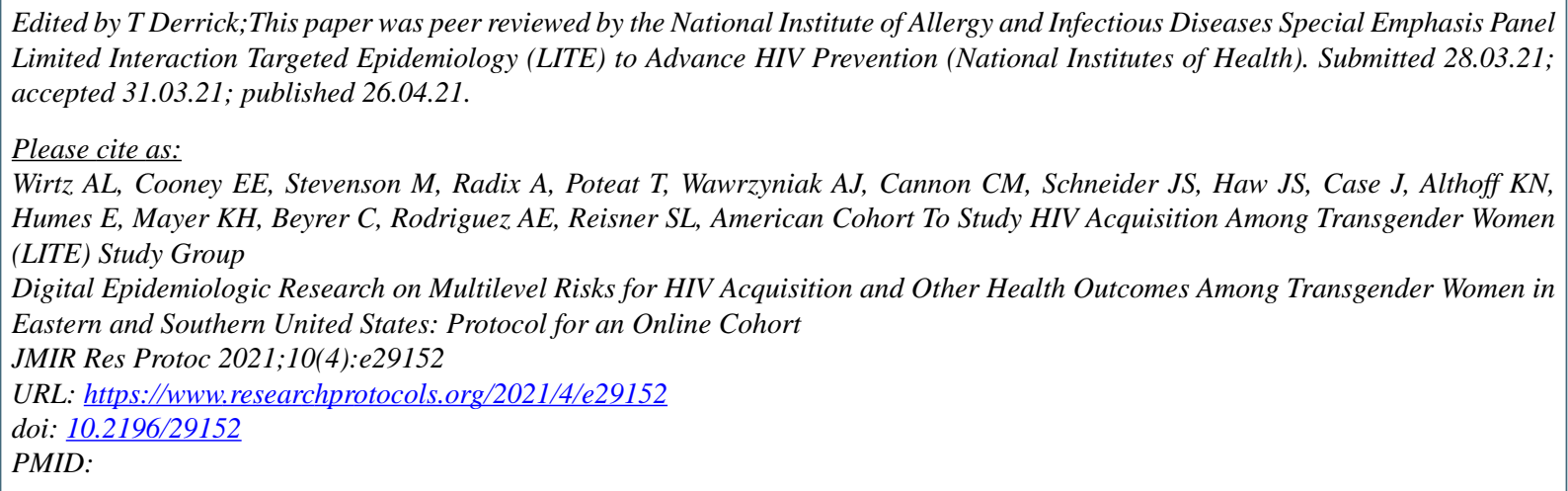

(CAndrea L Wirtz, Erin E Cooney, Megan Stevenson, Asa Radix, Tonia Poteat, Andrew J Wawrzyniak, Christopher M Cannon, Jason S Schneider, J Sonya Haw, James Case, Keri N Althoff, Elizabeth Humes, Kenneth H Mayer, Chris Beyrer, Allan E Rodriguez, Sari L Reisner, American Cohort To Study HIV Acquisition Among Transgender Women (LITE) Study Group. 
Originally published in JMIR Research Protocols (https://www.researchprotocols.org), 26.04.2021. This is an open-access article distributed under the terms of the Creative Commons Attribution License (https://creativecommons.org/licenses/by/4.0/), which permits unrestricted use, distribution, and reproduction in any medium, provided the original work, first published in JMIR Research Protocols, is properly cited. The complete bibliographic information, a link to the original publication on https://www.researchprotocols.org, as well as this copyright and license information must be included. 